Dr doc. Svitlana Vdovtsova

Department of social management

Ternopil institute of social and informative technologies

vdovtsova@yahoo.com

\title{
MOTIVATION MECHANISMS OF YOUTH BEHAVIOR ON UKRAINIAN LABOUR MARKET
}

\begin{abstract}
In the article it has been analyzed the main motivation mechanisms of youth behavior on today labour market (on the Ukraine statistics committee information and questionnaire research results of youth intensive intentions in relation to employment conducted in countries of Central and Easten Europe).
\end{abstract}

Key words: motivation mechanisms, labour market, level of young people economic activity, social and professional orientations, economic activity. 